\title{
PEMANFAATAN SAMPAH BEKAS BOTOL PLASTIK SEBAGAI BAHAN KURSI UNTUK AKTIVITAS SERVICE LEARNING MATA KULIAH CREATIVE PRENEURSHIP
}

\author{
Shania Stacey Sengkey ${ }^{1}$, Devina Rosy Sutiono ${ }^{2}$, Jennifer Gunawan ${ }^{3^{*}}$, Yusita Kusumarini ${ }^{4}$ \\ 1,2,3,4 Program Studi Desain Interior, Fakultas Seni dan Desain, Universitas Kristen Petra \\ Л. Siwalankerto 121-131, Surabaya 60236 \\ *Penulis korespondensi; email: jennifergunawan@rocketmail.com
}

\begin{abstract}
Abstrak: Sampah yang menggunung merupakan salah satu masalah terbesar di perkotaan. Sementara itu, masalah perubahan iklim yang ekstrim dipengaruhi oleh penggunaan plastik yang berlebihan, seperti sampah botol minuman yang sangat sering dijumpai. Penggunaan botol plastik sangat memudahkan masyarakat, terutama dengan aktivitas masyarakat yang tinggi, botol plastik dapat langsung dibuang usai digunakan, sehingga dengan penggunaan botol plastik yang sangat banyak, maka jumlah sampah plastik yang dihasilkan juga sangat besar. Berangkat dari permasalahan tersebut, maka muncul suatu ide untuk mendaur ulang sampah bekas botol plastik dengan melibatkan mahasiswa serta pelaku UKM, dengan metode Service Learning dalam mata kuliah Creativepreneurship. Hasil dari aktivitas pembelajaran ini adalah furnitur kursi yang dudukannya terbuat dari sampah bekas botol plastik.
\end{abstract}

Kata kunci: Sampah botol plastik; service learning; creativepreneurship.

\begin{abstract}
One of the biggest problems in big cities is mounds of garbage. Meanwhile, the extreme climate change is partly caused by excessive use of plastic, especially beverage bottles, which are very often encountered. Plastic beverage bottles are indeed deemed very easy to use by the community, especially by people with high activities who consider it more practical to bring a plastic beverage bottle than a reusable bottle because It can be discarded immediately after use. Because of that, the number of garbage produced is also very high. Responding to this problem, the idea emerged to recycle used plastic bottles into chair boards, with service learning method, through the subject Creativepreneurship. The result of the learning process is using recycled plastic bottles as chair boards.
\end{abstract}

Keywords: Plastic beverage bottles; service learning; creativepreneurship.

\section{PENDAHULUAN}

Permasalahan di kota besar yang seakan tidak ada habisnya adalah sampah yang menggunung. Dilansir dari Jawa Pos Online, bahkan produksi sampah plastik setiap harinya di Kota Surabaya adalah sekitar 400 ton. Sedangkan seperti yang telah kita ketahui, plastik merupakan salah satu material yang tidak bisa mengurai dengan sempurna, yang dengan kata lain tidak dapat terurai secara alami, sehingga memberikan pengaruh yang sangat buruk bagi lingkungan sekitar, apalagi untuk ekosistem lingkungan hidup. Salah satu sampah plastik yang paling lumrah ditemukan, adalah sampah botol minum kemasan. Botol minum kemasan plastik ini sangat memudahkan masyarakat karena praktis, dan dapat dibuang usai satu kali penggunaan, sehingga sesuai dengan penggunaan plastik yang sangat banyak, maka sampah yang dihasilkan pun menggunung. Adapun salah satu alternatif yang digunakan untuk meminimalisir jumlah sampah botol plastik yang semakin bertambah setiap hari adalah dengan mendaur ulang sampah bekas botol plastik dengan menjadi dudukan furnitur kursi.

Sementara itu, Creativepreneurship adalah mata kuliah dengan menggunakan metode Service Learning yang mengajak mahasiswa untuk membuat produk kreatif dengan menggandeng pelaku UKM, agar selain berupaya menyelamatkan lingkungan, pelaku UKM juga dapat menciptakan suatu usaha baru dan bermanfaat bagi masyarakat umum dan lingkungan sekitar. Dari latar belakang tersebut, masalah yang dapat dijabarkan sebagai berikut:

1. Bagaimana cara meminimalisir penggunaan sampah botol plastik sekaligus memberdayakan UKM yang ada di Surabaya

2. Bagaimana mata kuliah Creativepreneurship merespon keadaan terkait masalah sampah botol plastik?

3. Pembelajaran apa saja yang diperoleh dari kegiatan Service-Learning dalam mata kuliah Creativepreneurship? 


\section{METODE PELAKSANAAN}

Mata Kuliah Creativepreneurship mengajarkan mahasiswa untuk dapat menjadi pengusaha yang dapat memberdayakan tenaga masyarakat. Produk yang dipasarkan merupakan produk kreatif yang terbuat dari sampah daur ulang.

Creativepreneurship adalah ilmu yang mempelajari tentang teknologi, analitikal dan berpikir kreatif, membuat dan pengembangan bisnis, serta Service Learning. Untuk mencapai hal tersebut mahasiswa melakukan eksplorasi di Surabaya mengenai situasi lingkungan, sumber daya alam atau materi serta sumber daya manusia. Dari hasil eksplorasi tersebut mahasiswa mengidentifikasikan permasalahan lingkungan, sosial dan ekonomi.

Sehingga, tujuan dari Mata Kuliah Creativepreneurship adalah mengajak mahasiswa agar dapat mempelajari permasalahan yang ada di Surabaya dan mencari solusi dari permasalahan tersebut dengan memperhatikan aspek-aspek yang ada dan menerapkannya dalam desain serta bertanggung jawab akan hasil dari solusi kreatif desain tersebut, sehingga dapat dijual di masyarakat luas.

Metode kegiatan yang diterapkan adalah pendekatan Service Learning dan design thinking. Metode pendekatan Service Learning adalah kegiatan yang membutuhkan interaksi secara langsung antara mahasiswa dengan UKM untuk membuat produk yang akan dipasarkan di masyarakat umum. Service Learning menurut para ahli adalah sebagai berikut [3]:

Menurut Darby, Avital, Jenna, \& Haglund (2013: 185), Service Learning merupakan pembelajaran yang mengaplikasikan ilmu dalam kehidupan nyata terhadap suatu lingkungan atau kelompok.

Menurut Lake \& Jones (2008: 2146), Service Learning merupakan pembelajaran yang berhubungan dengan pelayanan yaitu dengan belajar akademik, perkembangan karakter, dan tanggung jawab.

Sedangkan menurut Howard (Bagerrly, 2006: 245), Service Learning adalah proses dari integrasi terhadap kurikulum program sukarelawan, dan didampingi dengan kurikulum yang memperdalam tentang pemahaman anak.

Dari beberapa definisi menurut para ahli di atas dapat disimpulkan bahwa metode Service Learning merupakan sebuah metode pembelajaran yang mengaplikasikan teori ke dalam praktek langsung yang mengutamakan sebuah pelayanan baik untuk diri sendiri, masyarakat, maupun lingkungan.
Terdapat metode lain yang mendukung menemukan solusi untuk menjawab permasalahan yang ditemukan adalah metode design thinking. Metode ini bertujuan untuk mendapatkan solusi kreatif dari permasalahan banyaknya sampah botol plastik di Surabaya.

5 tahapan design thinking yang digunakan sebagai berikut:

1. Empathize

Tahapan empathize dilakukan dengan cara melakukan studi literatur dan eksplorasi lapangan untuk mencari tahu permasalahan lingkungan, sosial, dan ekonomi.

2. Define

Tahapan define dilakukan dengan cara menganalisa permasalahan yang ada di Surabaya untuk dapat dijadikan dasar dari produk yang akan dibuat dan melakukan eksplorasi UKM.

3. Ideate

Tahapan ideate dilakukan dengan browsing internet untuk mencari inspirasi desain produk kursi. Kemudian, membuat beberapa alternatif desain produk kursi di aplikasi SketchUp agar mengetahui gambaran produk kursi yang menyerupai bentuk asli sebelum membuat prototype.

4. Prototype

Tahapan prototype dilakukan dengan mengimplementasikan ide dan membuat beberapa produk kursi dari alternatif-alternatif desain dengan skala 1:1.

5. Test

Tahapan test dilakukan dengan uji coba produk kursi, dengan tujuan agar produk ini mendapat masukan dari rekan-rekan mahasiswa, dosen, maupun masyarakat umum.

Kegiatan service learning Mata Kuliah Creativepreneurship 2019 diadakan pada tanggal 8 Februari 2019 sampai 20 Juni 2019.

\section{PELAKSANAAN KEGIATAN}

Pembuatan produk yang dapat meresponi masalah sampah plastik yang kian menggunung ini menggunakan tahapan-tahapan sebagai berikut:

\section{Empathize}

Tahap ini melakukan studi literatur yang berkaitan dengan eksplorasi lapangan dan menemukan bahwa salah satu masalah yang genting di kota besar khususnya Surabaya adalah masalah ekologi, berupa menumpuknya sampah, terlebih khusus sampah plastik. Salah satu jenis sampah plastik yang paling sering ditemui adalah sampah minuman plastik. 


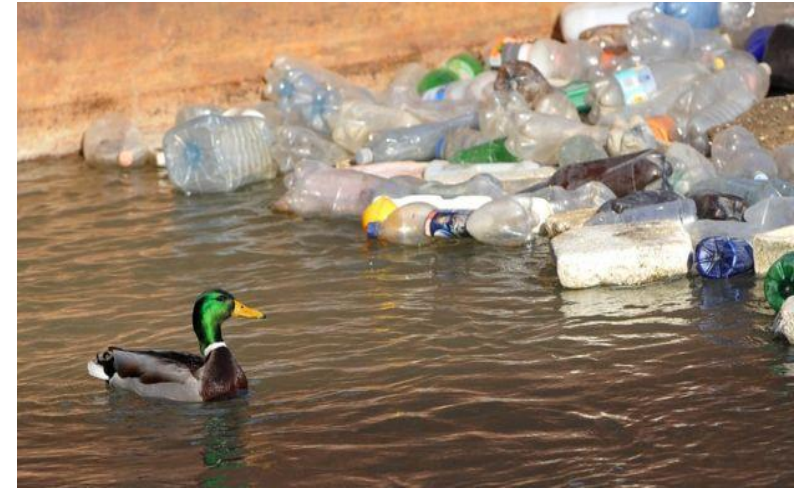

Gambar 1. Permasalahan ekologis yang nampak, yaitu sampah plastik yang menggunung.

\section{Define}

Setelah menemukan permasalahan yang ada di kota Surabaya, solusi untuk mengurangi sampah plastik adalah mendaur ulang sampah plastik menjadi produk yang berguna bagi masyarakat. Selain itu, menemukan ide usaha kreatif dengan membuat furnitur yang fungsional, bermanfaat, dan dapat memberdayakan UKM-UKM yang ada di Surabaya. Tujuannya agar para pelaku UKM dapat lebih berkembang dan menciptakan suatu usaha baru yang bermanfaat bagi lingkungan sekitar.

Terdapat 2 UKM yang digunakan yaitu, UKM Robries Gallery yang berfokus dalam pengolahan sampah plastik dan UKM CV Karya Indah selaku jasa tukang besi.

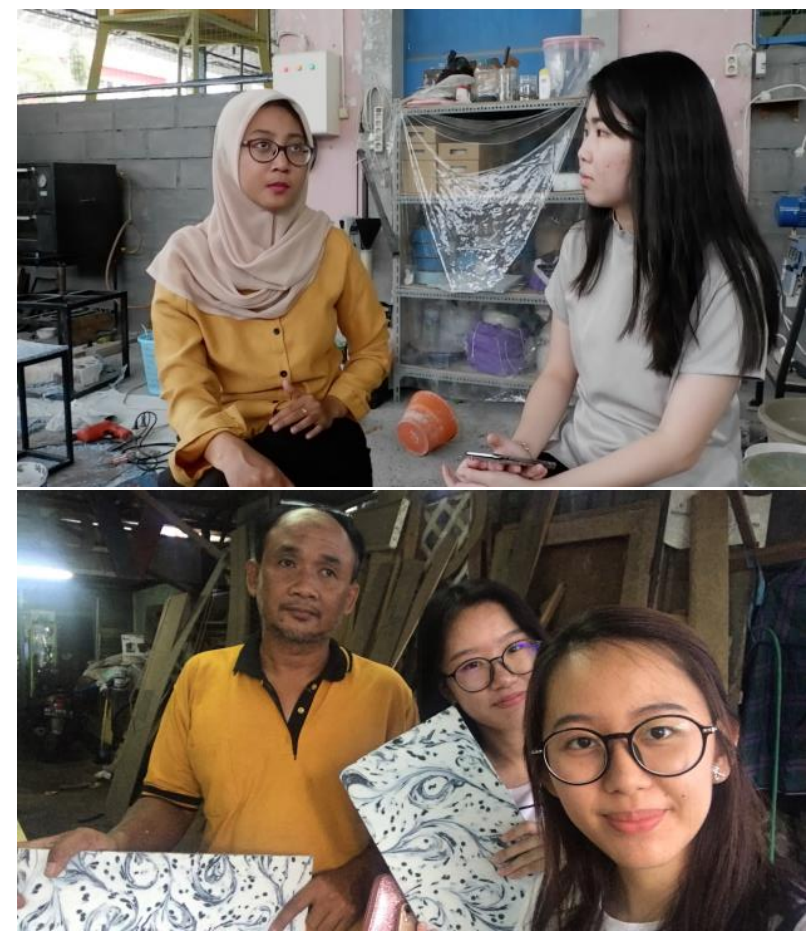

Gambar 2. Pertemuan dengan UKM Robries (foto atas) dan UKM jasa tukang besi CV Karya Indah (foto bawah)

\section{Ideate}

Tahap ini membuat ide desain produk kursi. Proses yang dilakukan adalah membuat sketsa gambar kursi yang akan dibuat, membuat $3 D$ model di aplikasi SketchUp, serta mendiskusikan dengan para pelaku UKM tentang kemungkinan apakah ide produk yang sudah penulis buat dapat direalisasikan atau tidak.
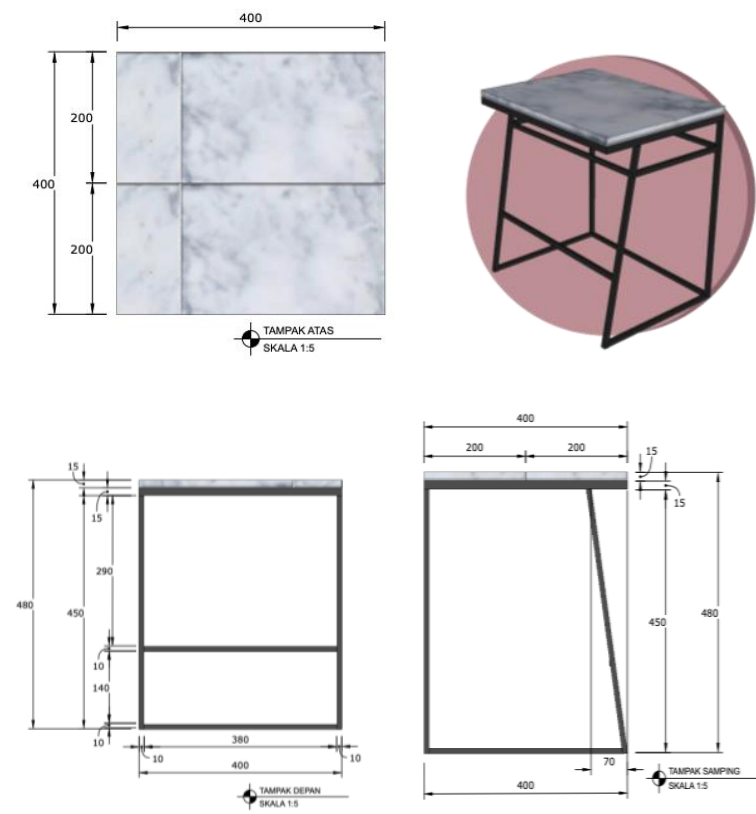

Gambar 3. Gambar kerja serta perspektif dari ide kursi.

\section{Prototype}

Pada tahap ini menyeleksi desain produk kursi yang akan diimplementasikan sebagai pembuatan produk 1:1. Dari beberapa alternatif desain, terdapat 3 buah desain terbaik yang layak untuk direalisasikan. Pembuatan papan kursi plastik diproduksi oleh UKM Robries Gallery, warna dari papan dudukan kursi dapat dipilih sesuai dengan keinginan konsumen. Setelah papan dudukan kursi plastik jadi, diserahkan kepada CV Karya Indah untuk membuat kerangka kaki kursi yang terbuat dari material besi.

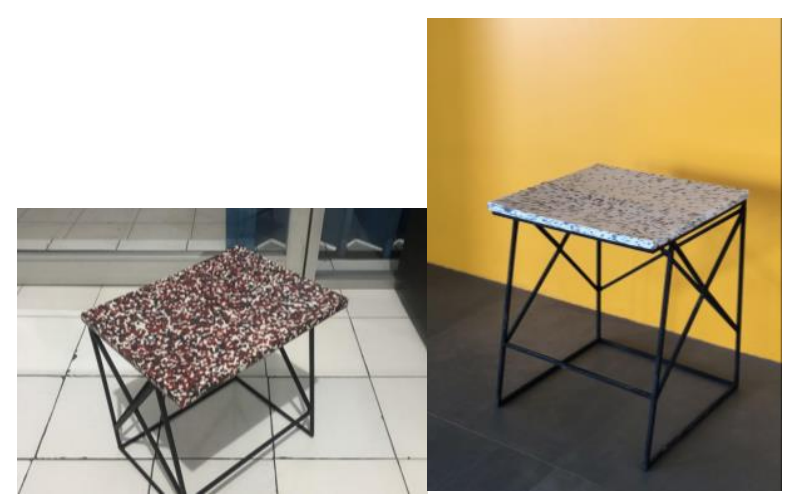




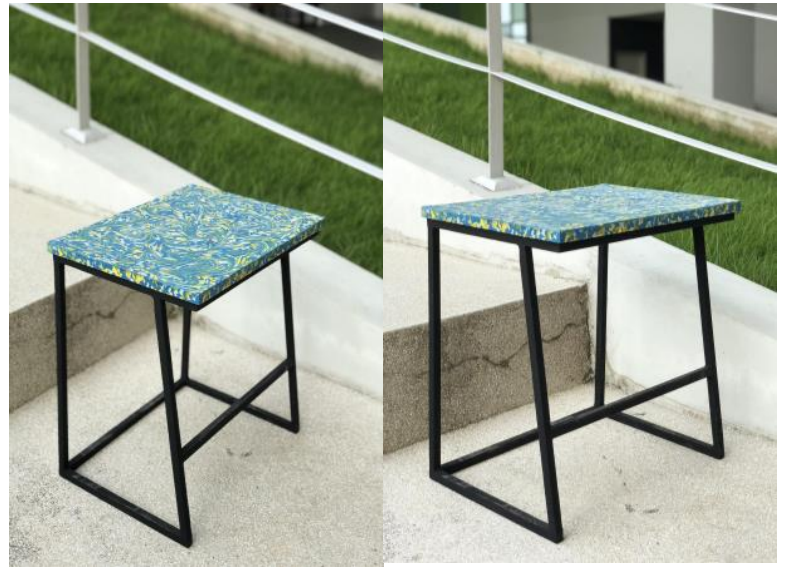

Gambar 4. Hasil jadi produk

\section{Test}

Setelah produk telah jadi, mata kuliah Creativepreneurship mengadakan bazaar yang terletak di Tunjungan Plaza 3 Convention hall pada tanggal 24-26 Mei 2019, agar produk hasil kegiatan Service Learning dapat dipamerkan dan dijual pada masyarakat umum. Dalam pameran itu masyarakat berkesempatan untuk menguji coba produk yang telah dibuat.

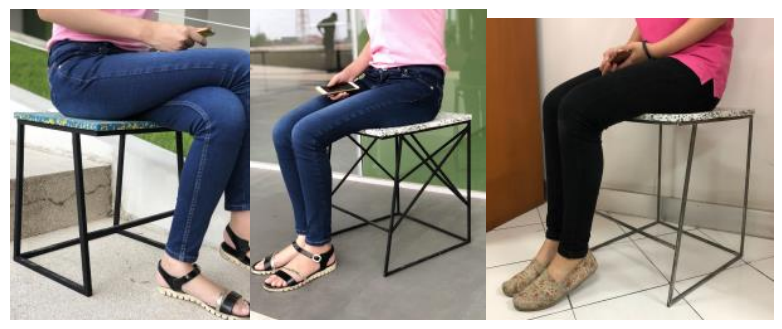

Gambar 5. Uji coba prototype

Selain itu, produk ini juga telah dievaluasi oleh dosen-dosen mata kuliah Creativepreneurship dan dosen - dosen Desain Interior Universitas Kristen Petra yang berkunjung ke bazaar. Saat acara bazaar juga telah diadakan peliputan oleh beberapa media, seperti Dwi Pekan Universitas Kristen Petra, Suara Surabaya, Kumparan, Berita Jatim, dan beberapa media lainnya. Kebanyakan media memberi respon positif atas kegiatan Service Learning yang dilakukan, terlebih karena produk Kursita yang dibuat merupakan produk yang sustainable karena berasal dari sampah plastik yang didaur ulang.

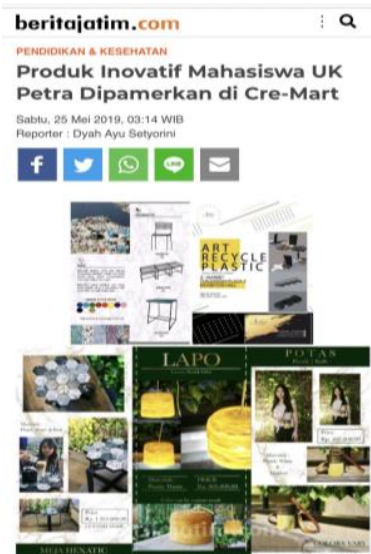

Surabaya (beritiajatim.com) - Sejumlah 131 mahasiswa
Program Stuci Desain Interior UK Potra mengoglar pameran 19 Brand Startup Baru bertajuk Cre-Mart. Qeiaran apik ini

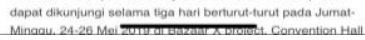

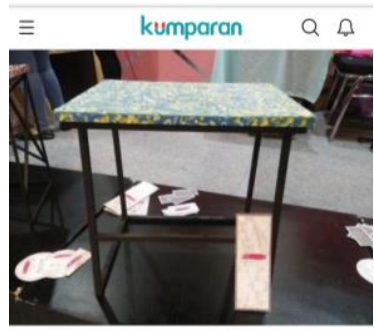

Prihatin dengan masalah sampah yang terus ada Gabriella Natali dan timnya membuat kursi dau
ulang dari tutup botol bekas yang dipanaskan menjadi lempengan tebal. Produk kursi ini dibe nama Kursita (ini kursi kita).

"Kami coba mengolah plastik botol dan kresek menjadi suatu inovasi yang unik," urai Gabriella atali sebagaa hetua kelompok Kursita saat ditemu

Kursita merupakan karya mahasiswa jurusan Desain
Interior UK Petra Surabaya yang dipamerkan di Cremart dalam acara Bazaar X Project, Convention Hal

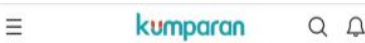

Ada Kursi Daur Ulang dari Tutup Botol Bekas di Bazaar X Project

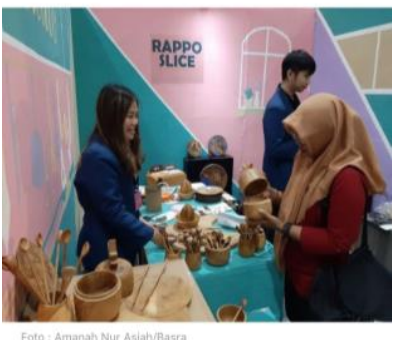

Persoalan sampah di Indonesia tak bisa dipandang sebelah mata. Data terbaru, Indonesia menjadi negara kedua pembuang sampah plastik ke laut yang terbanyak di dunia setelah Tiongkok. Tentu masih. lekat di ingatan tentang penemuan bangkai seek paus sperma (Physeter Macrocephalus) pada Mingus sore, 18 Nover ber 208 di

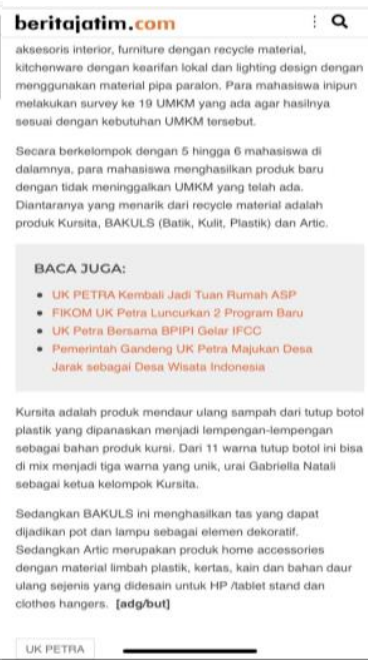

a

kumparan Q

"Semua ini kami buat handmade dengan bantua UMKM. Kami yang mendesain produknya, para Len

Sebanyak 131 mahasiswa Program Studi Desain Interior UK Petra menggelar pameran bertajuk CreMart. Dalam pameran ini para mahasiswa
bekerjasama dengan 19 UMKM yang ada di bekerjasama dengan 19 UMKM yang ada di Surabaya untuk menghasilkan 19 brand startup baru. Mariana Wibowo selaku dosen pengampu mata kuliah Creativepreneurship mengatakan, jika dala pameran ini para mahasiswa diajarkan mengenai
metode learning service. Sehingga mahasiswa tidak menjadi entrepreneur biasa, tetapi sosio entrepreneur yang memperhatikan sosial di masyarakat.

"Jadi para mahasiswa diminta membantu UMKM d sekitar Surabaya untuk menghasiikan produk yang

Dreati, hovetr dan berdaya jual tingi," ungkaphy palam pameran yang dihelat selba tiga hari berupa aksesoris interior multifungsi dengan fashion, aksesoris interior, furniture dengan recycle material, kitchenware dengan kearifan lokal dan

Pamerkan Produk 19 Brand Startup, UK Petra Gelar Cre-Mart

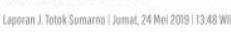

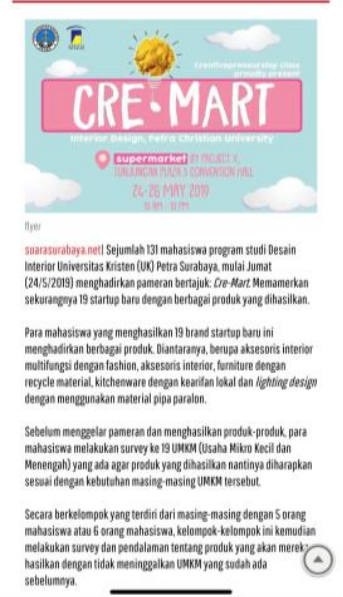




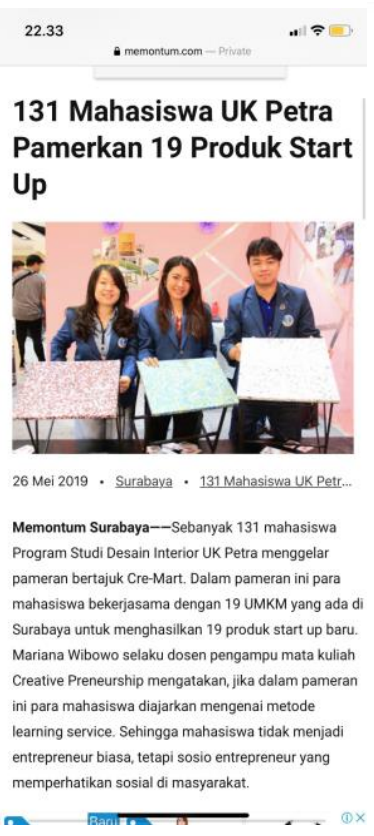

Dari suvey, pengkajian serta pendalaman yang dilakukan masing.

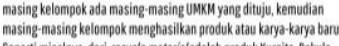

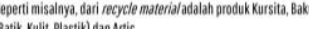

Kursitita adalah produk mendaur ulang sampan dari itutup botol plastik Jang dipanassan sedemikikn nupa sehingega menjadil lempenganempengan sebagä bahan yang dipakai dan dikxeasikan sebagai bath

Kamigunakan II warna tutup boto yang kemudian kami panaskian dan bentuk sedemikian rupa sehingzara menghiasilkan 3 warma yang baru,

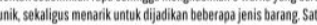
diantaranya untuk membuat Kursi', terang Gabriella Natalie ketu kelompok Kursita

Sedanglan Bakuls, menghasilkan tas yang dapat tijadikan pot dan

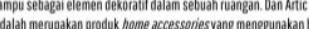
idalah merupakan produck home accessoniesyang mengegunakan bahan ulang yang diproses dan divessin untuk handphone, tablet stand dan clothes hangers.

Ditemui ditempat berbeda, Or. Yusita Kusumanini S.Sn, M.0s. bersama

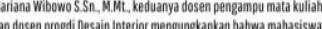

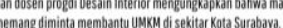

"Produkyang dipamerkan inim mervaakan project dari gabungan dua kelas mata kuliah yaitu creativepreneurship dengan metode sevic

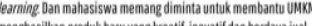

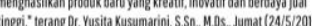

Karya produk mahasiswa prodi Desain Interior Universitas Kristen (US Petra Surabay dalam pameran Cre-Mart digelardi Bazaar Project,

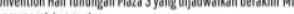

Gambar 6. Liputan dari media mengenai kegiatan Service Learning yang dilakukan di mata kuliah Creativepreneurship, terutama kelompok Kursita.

Setelah kegiatan bazaar selesai, para mahasiswa dan mitra UKM melakukan refleksi dan juga melakukan survei untuk melihat manfaat dari metode Service Learning ini menurut masyarakat umum. Survei dilakukan pada 40 orang, 25\% (10 orang) merupakan mahasiswa Universitas Kristen Petra, dan 75\% (30 orang) merupakan masyarakat umum (diluar civitas akademika Universitas Kristen Petra). 62.5\% (25 orang) responden sebelumnya belum mengetahui bahwa ada produk kursi yang terbuat dari sampah plastik, sedangkan sisanya yaitu $37.5 \%$ (15 orang) sudah mengetahui bahwa ada produk yang terbuat dari sampah plastik. Menurut hasil responden yaitu, 85\% (34 orang) berpendapat bahwa kursi ini merupakan produk yang menarik. Selain itu, seluruh responden berpendapat bahwa baik para UKM (Robries Gallery dan CV Karya Indah) maupun mahasiswa mendapatkan manfaat dari metode Service Learning yang telah dilakukan.

Produk ini juga mendapat beberapa saran dari para responden yang mengisi survei, beberapa diantaranya berpendapat bahwa produk ini sudah kreatif, inovatif, dan mempunyai nilai jual. Kebanyakan responden berharap bahwa kedepannya produk ini dapat dikembangkan dengan berbagai desain yang lebih variatif seperti contohnya dibuat dengan ada sandarannya, dibuat model bench, bisa dilipat, dan dibuat dengan berbagai macam ukuran. Beberapa responden juga menyarankan untuk membuat furnitur lain dari bahan dasar plastik yang didaur ulang, seperti meja, kitchen cabinet, rak, dan lemari.

\section{REFLEKSI}

Refleksi bertujuan untuk mengambil pembelajaran apa yang didapat dari kegiatan Service Learning yang telah dilakukan di Mata Kuliah Creativepreneurship. Mahasiswa mendapat ilmu baru dengan mengetahui material-material yang dapat diolah menjadi produk baru untuk dipasarkan. Setelah melakukan kegiatan Service Learning, penulis berpendapat bahwa mahasiswa telah mendapat tambahan ilmu, terutama tentang konstruksi material dan sifat - sifat material yang digunakan. Selain penulis, mitra UKM juga mendapatkan manfaat dari kegiatan Service Learning ini, berupa bertambahnya skill dan alternatif dalam membuat desain produk dari material dan jasa yang mereka sediakan.

\section{SIMPULAN}

Setelah pelaksanaan mata kuliah Creativepreneurship tahun 2019, berikut kesimpulan yang dapat dikemukakan:

1. Pembelajaran yang didapat dari Mata Kuliah Creativepreneurship 2019 tidak hanya memberi manfaat berupa menciptakan suatu ide kreatif dari permasalahan yang ada, namun juga mengajak mahasiswa untuk memberdayakan masyarakat sekitar mengembangkan usaha bisnis.

2. Pembelajaran Mata Kuliah Creativepreneurship 2019, tidak hanya meningkatkan kemampuan hardskill mahasiswa, namun kemampuan softskill mahasiswa juga diasah dengan diajak untuk berperan aktif dalam berkomunikasi serta memberdayakan masyarakat menjadi mitra untuk mengembangkan skill serta potensi yang dimiliki.

3. Solusi dari permasalahan lingkungan yang berupa sampah plastik yang menumpuk adalah dengan mendaur ulang menjadi suatu produk yang fungsional serta bermanfaat, yaitu KURSITA, yang dudukannya terbuat dari lempengan tutup botol minuman plastik yang dilelehkan dan digabungkan dengan besi sehingga menjadi kursi. Produk kursi ini pun kedepannya akan terus penulis kembangkan agar dapat membawa dampak positif yang lebih besar bagi masyarakat umum.

\section{UCAPAN TERIMA KASIH}

Penulis mengucapkan terima kasih kepada ibu Mariana Wibowo, S.Sn., M.MT. selaku dosen mata kuliah Creativepreneurship yang telah memberi penulis kesempatan untuk mengikuti bazaar Cre-Mart di Tunjungan Plaza. Penulis juga 
berterima kasih kepada UKM Robries Gallery yang telah membantu dalam proses pembuatan papan dudukan kursi, dan kepada Bapak Muchsin pemilik CV Karya Indah yang berperan dalam pembuatan kaki kursi dan memberi saran dan masukan pada penulis mengenai konstruksi kaki kursi yang terbaik untuk produk ini. Terima kasih juga penulis ucapkan kepada masyarakat umum dan mahasiswa Universitas Kristen Petra yang telah berpartisipasi dalam survei yang penulis buat.

\section{DAFTAR PUSTAKA}

Baggerly, J. (2006). Service learning with children affected by poverty: Facilitating multicultural competence in counseling education students. Journal of Multicultural Counseling and Development, 34(4), 244-255.

Darby, A., Longmire-Avital, B., Chenault, J., \& Haglund, M. (2013). Students' motivation in academic service-learning over the course of the semester. College Student Journal, 47(1), 185-191.
Evelin, M., Feliecia Angelina, \& Yusita Kusumarini. (2018). Respon ekologis dan kreatif beban limbah furnitur rusak di institusi pendidikan. Share, Journal of Service Learning, 4(2), 37-44.

Kusnaedi, Iyus. 2018. Eksplorasi Sampah Plastik Menggunakan Metode 'Heating' Untuk Produk Pakai. Seminar Nasional Rekayasa dan Desain Itenas 2018, Tema: Peranan Rekayasa dan Desain dalam Percepatan Pembangunan Nasional Berkelanjutan. Kampus Institut Teknologi Nasional. Bandung.

Lake, V. E., \& Jones, I. (2008). Service Learning in Early Childhood Teacher Education: Using Service to Put Meaning Back Into Learning. Teaching and Teacher Education, 24(8), 21462156.

Santoso, M, Christine Yulie Kurrniawan, \& Yusita Kusumarini. (2018). Perancangan Fasilitas Display Maket Furniture Menggunakan Material Bekas Bangunan dan Furniture Kampus. Share, Journal of Service Learning, 5(2), 56-61.

Yuliani, S, Andereas, P, S. (2019). Eksperimen Material Sampah Laut Sebagai Material Pendukung Ruang Interior. Share, Journal of Service Learning, 7(2), 24-29. 